\title{
Current epidemiological profile and features of visceral leishmaniasis in People's Republic of China
}

\author{
Jun-Yun Wang ${ }^{1 *}$, Gang Cui ${ }^{2}$, Hai-Tang Chen ${ }^{1}$, Xiao-Nong Zhou' ${ }^{1}$ Chun-Hua Gao ${ }^{1}$ and Yue-Tao Yang ${ }^{1}$
}

\begin{abstract}
Background: Visceral leishmaniasis $(\mathrm{VL})$ is still an important public health problem in China. In recent years endemic regions spread, prevalence increased, and even an outbreak of the disease occurred in China due to global warming and population movement. It is essential to elucidate the current epidemic situation and epidemiological characteristics of VL for designing control policy. In the present study we describe the current epidemiological profile and characteristics of VL in China based on retrospectively reviewing of $V L$ cases reported between 2005 and 2010 by a passive surveillance system.

Methods: The present study was a retrospective review of VL cases notified between 2005 and 2010 based on the passive surveillance data. The data were tabulated, diagrammatized and analyzed through descriptive statistics in a Microsoft Excel spreadsheet.
\end{abstract}

Results: A total of $2450 \mathrm{VL}$ cases were notified, with a mean of 408 cases per year. 61 counties were identified as endemic area with 2224 autochthonous cases, and the other 118 counties as non-endemic areas with 226 imported cases. 97.71\% of cases were concentrated in Xinjiang, Gansu and Sichuan Provinces. 9 major counties reported a mean of $>10$ cases per year, with a total of 1759 cases reported. Different types of VL revealed distinct epidemiological characteristics.

Conclusions: The number of VL cases and endemic counties both increased in the period 2005-2010 in China. Different type or sub-type of $V L$ revealed distinct epidemiological characteristics. Therefore, differential control measures must be taken in different endemic areas against incidence increase and endemic area spread.

\section{Background}

Leishmaniasis is a mammalian disease caused by parasitic protozoans classified as Leishmania species (Kinetoplastida, Trypanosomatidae) [1-3]. The disease has different clinical forms, ranging from a skin ulcer (cutaneous leishmaniasis, CL), which can heal spontaneously, to the most severe form of visceral leishmaniasis, which can lead to the patient's death when untreated [4]. Natural transmission may be zoonotic or anthroponotic by the bite of a phlebotomine sandfly species of the genera Phlebotomus (Old World) and Lutzomyia (New World) [3,5-8].

\footnotetext{
* Correspondence: wang_junyun@yahoo.com

'National Institute of Parasitic Diseases, Chinese Center for Disease Control and Prevention; the Key Laboratory of Parasite and Vector Biology of the Chinese Ministry of Health; WHO Collaborating Center for Malaria,

Schistosomiasis and Filariasis, Shanghai 200025, People's Republic of China Full list of author information is available at the end of the article
}

Leishmaniasis is endemic in 98 countries or territories, with more than 350 million people at risk. The global incidence is estimated to be 2 million new cases per year ( 0.5 million of VL and 1.5 million of CL). VL causes an estimated 50,000 deaths annually, a rate surpassed among parasitic diseases only by malaria, and 2,357,000 disability-adjusted life years lost, placing leishmaniasis ninth in a global analysis of infectious diseases [9]. Desjeux [8] indicated that in the previous decade endemic regions had spread, prevalence had increased and the number of unrecorded cases must have been substantial, because notification was compulsory in only few countries [10]. Therefore, the public health impact of the disease worldwide has been grossly underestimated $[1,10]$.

VL has been and is still an important public health problem in China. Prior to the initiation of a national control program in 1951, VL was one of the major

\section{Biomed Central}

(c) 2012 Wang et al; licensee BioMed Central Ltd. This is an Open Access article distributed under the terms of the Creative Commons Attribution License (http://creativecommons.org/licenses/by/2.0), which permits unrestricted use, distribution, and reproduction in any medium, provided the original work is properly cited. 
parasitic diseases in the People's Republic of China, endemic in 17 provinces, municipalities and autonomous regions. According to the available epidemiological data, there were about 530,000 VL cases in China in 1951 [11]. Following great efforts in the frame of the national control program, the disease has been largely brought under control in the eastern regions of the country. However, the disease is still endemic or occurs sporadically in 43 counties in six provinces or autonomous regions in western China (namely Xinjiang, Gansu, Sichuan, Shaanxi, Shanxi and Inner Mongolia) in the 1990s [12-15].

Two epidemiological types of VL can be distinguished in western China based on infected Leishmania species and source of infection $[13,16]$. The first one is an anthroponotic type of VL (AVL) caused by L. donovani, and currently is endemic in the oases of the plains of Kashi prefecture, Xinjiang Uygur Autonomous Region. Most cases occur in young people and adults. The transmitting cycle is from human to human and no animal host has been found (0-0.3\%) [11]. The widely distributed peridomestic Phlebotomus longiductus, an endemic species in Xinjiang, is the vector [17].

The second one is zoonotic type caused by L. infantum with an animal host as the principal source of infection. This type has been divided into two subtypes, namely a mountainous and a desert sub-type based on the ecosystem and epidemiological characteristics, i.e. geographical and landscape characteristics, age distribution of patients, vector sandfly species and their ecology, and source of infection $[13,16,18,19]$. The mountainous sub-type of zoonotic VL (MST-ZVL) occurs in the western mountainous and hilly regions of Gansu, Sichuan, Shaanxi and Shanxi provinces. Patients are mostly children less than ten years old. High Leishmania spp. infection rates in dogs were detected [20,21] and elimination and prohibition of dogs markedly reduced the number of human cases, thus dogs are likely to be the principal source of infection for the subtype [13]. The vector of this form is wild $P$. chinensis, a zoophilic species that also feeds on man. During daytime, these sandflies rest mainly in caves and other shelters but they enter villages after sunset [17]. The desert sub-type of zoonotic VL (DST-ZVL) is endemic in the northwestern desert regions of China, including Xinjiang, western Inner Mongolia and northern Gansu [19]. Patients are mostly infants less than one year old [16]. These regions were uncultivated deserts before they were populated by immigrants who introduced agricultural activities. Consequently, autochthonous infantile VL occurs, and the region is considered to be a natural nidus of kala-azar infected wild animals presumably being the source of infection. However, which animals are a source of infection are unknown [16]. The wild species, $P$. wui and $P$. alexandri, are the vectors infesting the specific landscapes, such as dry desert region or the stony desert, respectively [22].

Since the disease in major endemic areas was under control with a nationwide control campaign implemented in 1950s it became neglected in China and no further surveillance and control measures was applied. In recent years endemic regions spread, prevalence increased, and even an outbreak of the disease occurred in China due to global warming and population movement $[16,23,24]$. It is essential to elucidate the current epidemic situation and epidemiological characteristics of VL for designing control policy. However, there was not any national VL case reporting system or surveillance system before 2005 in China, VL case records and statistics were not available, and the information on accurate number of cases, geographic distribution etc., was not clear. From 2005, VL cases must be reported compulsorily in China according to the National Regulation on the Control of Communicable Diseases. In the present study we describe the current epidemiological profile and characteristics of VL based on reported cases between 2005 and 2010 .

\section{Methods}

The present study was a retrospective review of VL cases notified between 2005 and 2010 based on the passive surveillance data reported through the web-based National Diseases Reporting Information System (NDRIS) operated by the Chinese Center for Disease Control and Prevention. In China, VL cases must be compulsorily reported through NDRIS according to the National Regulation on the Control of Communicable Diseases from 2005 [25]. All reported VL cases were diagnosed in accordance with the National Criteria for Visceral Leishmaniasis Diagnosis in China and reported via NDRIS. Passive surveillance data covered personal and clinical information, including patient's name, age, gender, address and diagnosis etc. In this study the spatial, temporal, age, occupation and gender distribution of cases were analyzed. Data were tabulated, diagrammatized and analyzed through descriptive statistics in a Microsoft Excel spreadsheet, release 2003.

The study had been reviewed and approved by the Ethical Review Committee of the National Institute of Parasitic Diseases, Chinese Center for Disease Control and Prevention in Shanghai.

\section{Results}

\section{General status}

Between 2005 and 2010 a total of $2450 \mathrm{VL}$ cases were notified in China through NDRIS (Table 1). The yearly number of cases reported ranged from 287 to 539, with a mean of reported per year of 408 cases. In the period 
Table 1 Number of VL cases reported in China between 2005 and 2010

\begin{tabular}{|c|c|c|c|c|c|c|c|}
\hline Year & AVL & MST-ZVL & DST-ZVL & $\begin{array}{c}\text { Sub-total } \\
\text { (Endemic areas) }\end{array}$ & Non-endemic areas & Total & $\%$ \\
\hline 2005 & 119 & 125 & 47 & 291 & 30 & 321 & 13.10 \\
\hline 2006 & 91 & 139 & 31 & 261 & 26 & 287 & 11.71 \\
\hline 2007 & 79 & 194 & 50 & 323 & 54 & 377 & 15.39 \\
\hline 2008 & 63 & 179 & 253 & 495 & 29 & 524 & 21.39 \\
\hline 2009 & 79 & 193 & 225 & 497 & 42 & 539 & 22.00 \\
\hline 2010 & 75 & 180 & 102 & 357 & 45 & 402 & 16.41 \\
\hline Total & 506 & 1010 & 708 & 2224 & 226 & 2450 & 100 \\
\hline
\end{tabular}

of 2008 to 2009 the highest number of cases was reported due to the outbreak of the disease in Jiashi County of Xinjiang [16], with 1063 cases, accounting for $43.39 \%$ of the total cases reported between 2005 and 2010 (Table 1).

\section{Geographic distribution Differences in provinces}

The 2450 cases were distributed at 179 counties/cities, in 18 provinces/municipalities/autonomous regions (Table 2). 97.71\% (2394/2450) of cases occurred in three provinces/autonomous regions (namely Xinjiang, Gansu and Sichuan). The highest concentration (49.71\%) of reported cases was in Xinjiang $(\mathrm{n}=1218)$, followed by $33.67 \%$ in Gansu Province $(\mathrm{n}=825), 14.33 \%$ in Sichuan Province $(\mathrm{n}=351)$ (Table 3$)$.

\section{Differences in endemic and non-endemic areas}

Among 179 counties/cities, 61 counties/cities in six provinces/autonomous regions (33 in Xinjiang, 14 in Gansu, 6 in Sichuan, 4 in Shaanxi, 3 in Shanxi, and 1 in Inner Mongolia) were identified as VL endemic areas (Figure 1, Table 2) and reported 2224 autochthonous cases, accounting for $90.78 \%$ of the total reported cases in this period. The other 118 counties in 16 provinces/ municipalities/autonomous regions were non-endemic areas and reported 226 (9.22\%) imported cases (Table 2).

Out of 61 endemic counties/cities, 9 (14.75\%) major counties/cities (including Artux City, Kashgar City, Shufu County, Jiashi County and Bachu County of Xinjiang, Wudou County, Wenxian County and Zhouchu County of Gansu, and Jiuzhaigou County of Sichuan) (Table 4, Figure 2) reported means of more than 10 cases per year with a total of 1759 cases reported, accounting for $79.09 \%(1759 / 2224)$ of total cases from endemic counties/cities and for $71.80 \%(1759 / 2450)$ of total cases reported in China in this period. 33 (54.10\%) counties/cities reported means of less than 1 case annually. The other 19 (31.15\%) counties/cities reported means of cases $\geq 1$ and $<10$ annually.

Regarding the incidence rate, 7 counties/cities (including Jiashi County of Xinjiang, Wudou County, Wenxian
County, Zhouchu County and Diebu County of Gansu, and Jiuzhaigou County of Sichuan) (Table 4, Figure 2) was over $1 / 100,000$. The highest incidence rate $(2.87 /$ $100,000)$ was in Jiuzhaigou County of Sichuan, followed by $2.21 / 100,000$ in Jiashi of Xinjiang. The incidence rate in other counties was less than $2 / 100,000$. The major endemic counties/cities with means of more than 10 cases per year or with over $1 / 100,000$ incidence rate concentrated in two areas, namely, Kashi prefecture of Xinjiang and southern part of Gansu with adjacent Jiuzhaigou County of Sichuan (Figure 2).

In the period 2005 to 2010, $226 \mathrm{VL}$ cases were reported from 118 non-endemic counties/cities in 16 provinces/municipalities/autonomous regions (Table 2). 222 cases were infected in China, and the other 4 cases were infected in Spain, Nigeria and Algeria, respectively. Differences in natural environment

Among 61 endemic counties/cities, 13 counties/cities belong to an AVL endemic area and all concentrated in old oases in Kashi, Xinjiang, with 507 cases reported. 23 counties/cities (10 in Gansu, 6 in Sichuan, 4 in Shaanxi and 3 in Shanxi) belong to the MST-ZVL endemic area and are distributed in mountainous and hilly regions (including loess plateau), with 1009 cases reported. The other 35 counties/cities (20 in Xinjiang, 4 in Gansu and 1 in Inner Mongolia) are DST-ZVL and distributed in dry desert area and stony desert area, with 708 cases reported (Figure 1, Table 2).

\section{Demographic distribution \\ Age}

The age distribution of cases is showed in Table 5. The majority of imported cases $(87.17 \%)$ were in people of more than 14 years of age and the median age is 33.9 years. For the cases from endemic areas $44.65 \%$ occurred in the 0-2 years age group and the median age is 3.7 years. The age distribution of different types of VL was analyzed based on the case data of the major endemic counties/cities (including Artux, Kashgar, Shufu, Jiashi, Bachu, Wudou, Wenxian, Zhouchu, Diebu and Jiuzhaigou) listed in Table 4. For AVL, 43.04\% occurred in the $\geq 15$ years of age group with a median age of 
Table 2 VL cases distribution and endemic type between 2005 and 2010

\begin{tabular}{|c|c|c|c|c|}
\hline \multirow{3}{*}{ County/city } & \multirow{3}{*}{ No. of case } & \multicolumn{3}{|c|}{ Type of endemic area } \\
\hline & & \multirow[b]{2}{*}{ AVL } & \multicolumn{2}{|c|}{ ZVL } \\
\hline & & & MST-ZVL & DST-ZVL \\
\hline \multicolumn{5}{|l|}{ Xinjiang } \\
\hline Urumqi City & 8 & Yes & & \\
\hline Aksu City & 8 & Yes & & \\
\hline Wensu County & 2 & Yes & & \\
\hline Xayar County & 11 & Yes & & \\
\hline Wushi County & 28 & Yes & & \\
\hline Artux City & 64 & Yes & & \\
\hline Wuqia County & 4 & Yes & & \\
\hline Kashgar City & 243 & Yes & & \\
\hline Shufu County & 88 & Yes & & \\
\hline Shule County & 19 & Yes & & \\
\hline Yengisar County & 13 & Yes & & \\
\hline Shache County & 17 & Yes & & \\
\hline Xinhe County & 1 & yes & & \\
\hline Turpan City & 3 & & & Yes \\
\hline Hami City & 5 & & & Yes \\
\hline Korla City & 22 & & & Yes \\
\hline Luntai County & 16 & & & Yes \\
\hline Yuli County & 21 & & & Yes \\
\hline Ruoqiang County & 2 & & & Yes \\
\hline Zepu County Makit County & 2 & & & Yes \\
\hline Yopurga County & 5 & & & Yes \\
\hline Jiashi County & 10 & & & Yes \\
\hline Bachu County & 477 & & & Yes \\
\hline Minfeng County & 39 & & & Yes \\
\hline Tumushuke city & 2 & & & Yes \\
\hline Kuqa County & 40 & & & Yes \\
\hline Karamay City & 40 & & & Yes \\
\hline Toksun County & 1 & & & Yes \\
\hline Yanji County & 1 & & & Yes \\
\hline Baicheng County & 1 & & & Yes \\
\hline Awat County & 2 & & & Yes \\
\hline Moyu County & 1 & & & Yes \\
\hline 8 non-endemic counties/cities & 19 & & & \\
\hline \multicolumn{5}{|l|}{ Gansu } \\
\hline Wudou County & 327 & & Yes & \\
\hline Wenxian County & 262 & & Yes & \\
\hline Dangchang County & 34 & & Yes & \\
\hline Kangxian County & 1 & & Yes & \\
\hline Zhouchu County & 112 & & Yes & \\
\hline Diebu County & 42 & & Yes & \\
\hline Huanxian County & 5 & & Yes & \\
\hline Tongwei County & 2 & & Yes & \\
\hline Gangu County & 3 & & Yes & \\
\hline Linxia City & 2 & & Yes & \\
\hline Jiuqian City & 1 & & & Yes \\
\hline Jinta County & 3 & & & Yes \\
\hline Anxi County & 1 & & & Yes \\
\hline Denhuang City & 1 & & & Yes \\
\hline
\end{tabular}




\begin{tabular}{|c|c|c|c|c|}
\hline 16 non-endemic counties/cities & 28 & & & \\
\hline \multicolumn{5}{|l|}{ Sichuan } \\
\hline Wenchuan County & 10 & & Yes & \\
\hline Lixian County & 1 & & Yes & \\
\hline Maoxian County & 38 & & Yes & \\
\hline Heishui County & 47 & & Yes & \\
\hline Beichuan County & 4 & & Yes & \\
\hline Jiuzhaigou County & 107 & & Yes & \\
\hline 65 non-endemic counties/cities & 144 & & & \\
\hline \multicolumn{5}{|l|}{ Shaanxi } \\
\hline Yichuan County & 1 & & Yes & \\
\hline Shenmu County & 1 & & Yes & \\
\hline Qingjian County & 1 & & Yes & \\
\hline Ningqiang County & 4 & & Yes & \\
\hline 6 non-endemic counties/cities & 7 & & & \\
\hline \multicolumn{5}{|l|}{ Shanxi } \\
\hline Yangquan County & 3 & & Yes & \\
\hline Xianghuan County & 1 & & Yes & \\
\hline Wuxiang & 1 & & yes & \\
\hline \multicolumn{5}{|l|}{ Inner Mongolia } \\
\hline Ejni Banner & 9 & & & Yes \\
\hline \multicolumn{5}{|l|}{ Other 12 non-endemic provinces } \\
\hline 23 non-endemic counties/cities & 28 & & & \\
\hline$\overline{\text { Total }}$ & 2450 & 13 counties/cities & 23 counties/cities & 25 counties/cities \\
\hline
\end{tabular}

12.1 years. For MST-ZVL, the percentages were 33.61\%, $19.50 \%, 16.57 \%$, and 30.32 in the $0-2,3-6,7-14$ and $\geq 15$ years age groups, respectively, and the median age is 6.1 years. For DST-ZVL the majority of cases (93.70\%) occurred in the 0-2 years age group with the median age of 2.1 years.

\section{Occupation}

Regarding occupation, for imported cases labourers had the highest rate of VL infection (56.64\%). In endemic areas infants and young children had the highest rate of infection $(60.21 \%)$, followed by peasants $(18.12 \%)$ and students (15.70\%). The occupational distribution of different types of VL was analyzed based on the case data from the 9 major endemic counties/cities listed in Table 4. In AVL, students had the highest rate (33.67\%),

Table 3 The distribution of VL cases in major provinces

\begin{tabular}{cccccccc}
\hline Year & $\begin{array}{c}\text { China } \\
\text { NO. of case }\end{array}$ & \multicolumn{2}{c}{$\begin{array}{c}\text { Xinjiang } \\
\text { NO. of case \% }\end{array}$} & \multicolumn{2}{c}{$\begin{array}{c}\text { Gansu } \\
\text { NO. of case \% }\end{array}$} & \multicolumn{2}{c}{$\begin{array}{c}\text { Sichuan } \\
\text { NO. of case \% }\end{array}$} \\
\hline 2005 & 321 & 165 & 51.40 & 92 & 28.66 & 57 & 17.76 \\
2006 & 287 & 125 & 43.55 & 106 & 36.93 & 49 & 17.07 \\
2007 & 377 & 129 & 34.22 & 160 & 42.44 & 75 & 19.89 \\
2008 & 524 & 317 & 60.50 & 152 & 29.00 & 49 & 9.35 \\
2009 & 539 & 304 & 56.40 & 161 & 29.87 & 62 & 11.50 \\
2010 & 402 & 178 & 44.28 & 154 & 38.31 & 59 & 14.68 \\
\hline Total & 2450 & 1218 & 49.71 & 825 & 33.67 & 351 & 14.33 \\
\hline
\end{tabular}

followed by infants and young children (29.62\%), and peasants (29.62\%). For MST-ZVL, the highest rate of cases was in infants and young children (52.41\%), followed by peasants $(22.54 \%)$ and students (18.57\%). For DST-ZVL, most of cases were from infants and children (97.48\%) (Table 6).

\section{Gender}

The gender distribution of cases is shown in Table 7 . The ratio of males to females was 1:0.165, 1:0.678, 1:0.710, 1: 0.688, and 1:0.706 for non-endemic areas, endemic areas, AVL, MST-ZVL and DST-ZVL, respectively.

\section{Temporal distribution}

Year

In the period 2005-2010 the number of imported cases (from non-endemic areas) showed a slight difference year by year. While in endemic areas, reported cases increased from 2006, and reached the highest level in 2008 and 2009. Among them, reported cases increased year by year from 2005 to 2007 for MST-ZVL, and for DST-ZVL there was a sharp increase in 2008 and 2009 due to the outbreak occurring in Jiashi County of Xinjiang (Table 1).

Month

The monthly distribution of cases between 2005 and 2010 is shown in Figure 3. Cases were identified in all 


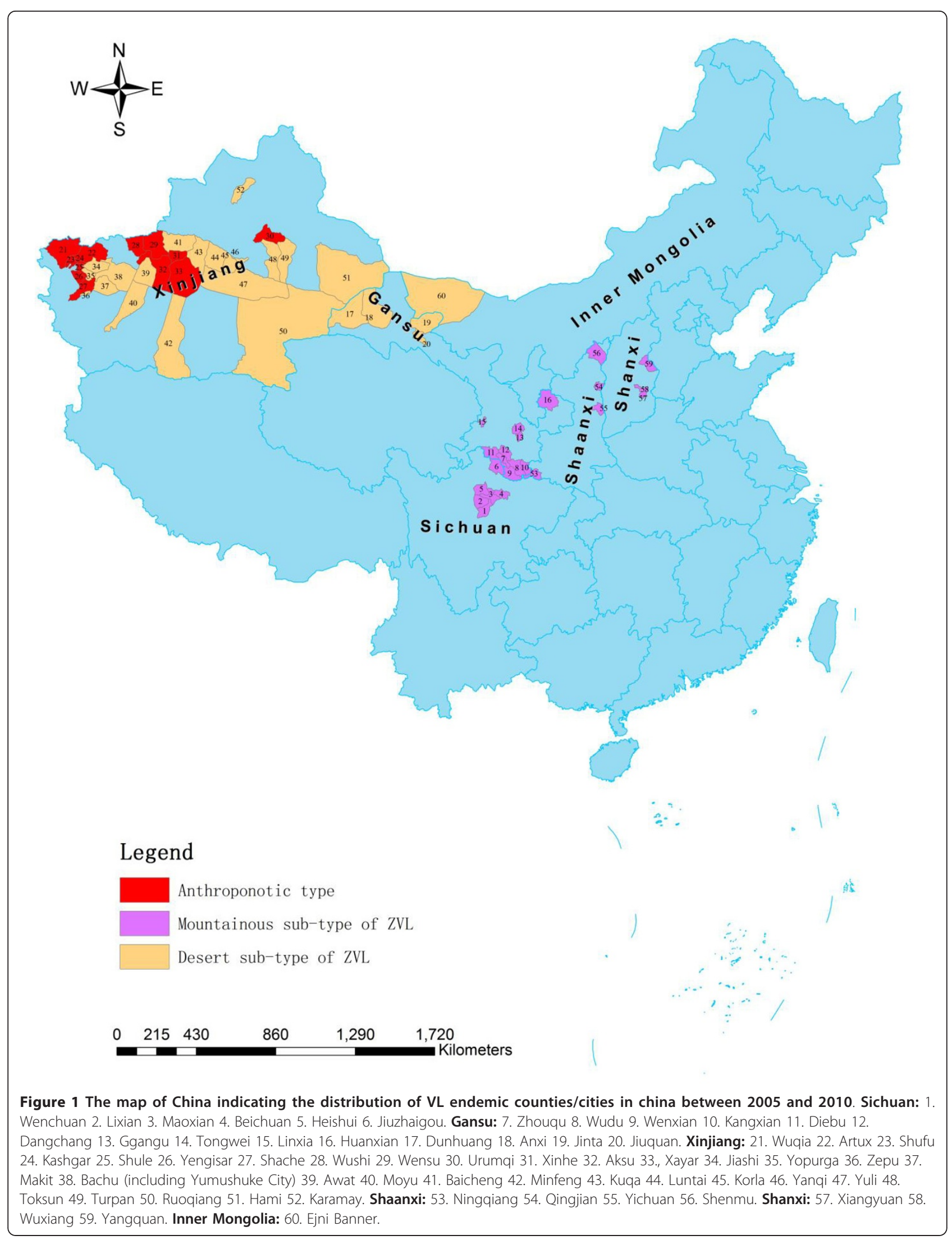


Table 4 No. of VL cases and incidence rate in major endemic counties/cities

\begin{tabular}{|c|c|c|c|c|}
\hline counties/cities & No. of case & $\begin{array}{c}\text { Average No. } \\
\text { of case per year }\end{array}$ & Population** & $\begin{array}{c}\text { Incidence rate } \\
(1 / 100000)\end{array}$ \\
\hline \multicolumn{5}{|l|}{ AVL } \\
\hline Artux City & 64 & 10.67 & 217,200 & 0.49 \\
\hline Kashgar City & 243 & 40.5 & 427,200 & 0.95 \\
\hline Shufu County & 88 & 14.67 & 303,200 & 0.48 \\
\hline \multicolumn{5}{|l|}{ Desert sub-type of ZVL } \\
\hline Jiashi County & 477 & 79.5 & 359,900 & 2.21 \\
\hline Bachu County (including Tumushuke city*) & 79 & 13.17 & 447,400 & 0.29 \\
\hline \multicolumn{5}{|l|}{ Mountainous sub-typeof ZVL } \\
\hline Wudou County & 327 & 54.5 & 520,100 & 1.05 \\
\hline Wenxian County & 262 & 43.83 & 238,500 & 1.84 \\
\hline Zhouchu County & 112 & 18.67 & 135,100 & 1.38 \\
\hline Diebu County & 42 & 7 & 53,400 & 1.31 \\
\hline Jiuzhaigou County & 107 & 17.83 & 62,200 & 2.87 \\
\hline Total & 1801 & 300.17 & $2,764,200$ & 1.09 \\
\hline
\end{tabular}

* Tumushuke city is located within Bachu County.

** 2007 census

months for each type of VL, however, monthly distribution of reported cases showed a difference with different type of VL. For AVL the cases increased in March and reached a peak in June. The second small peak appeared in January. For MST-ZVL a peak occurred in April. However, for the DST-ZVL the majority of cases were reported in the period of September to February of the next year, with a peak in December.

\section{Discussion}

The number of cases and endemic foci for VL has increased during the past two decades in the world [26-29]. A similar situation also occurred in China based on the results of this study. In the last six years a mean of 406 cases per year was reported with a $54.37 \%$ increase compared to a mean of 263 cases per year in the period of 1990-1999. 61 endemic counties/cities were identified with a $41.86 \%$ increase compared to 43 endemic counties/cities in the period of 1990-1999. In the last six years, endemic regions spread, such as Minfeng County of Xinjiang [23] or re-emerged, such as Gangu County of Gansu. Even an outbreak of the disease occurred in Jiashi County of Xinjiang in 2008-2009 with the highest incidence [16].

In China, different type or sub-type of VL (AVL, MSTZVL and DST-ZVL) revealed differences not only in geographical and landscape characteristics, Leishmania species, vector species and reservoir host, but also in age and monthly distribution of cases $[11,13,18,22,30,31]$. Previous observation showed that for AVL 8.3-38.9\% of the cases occurred under 5 year-old, with few infant cases. While for DST-ZVL, the majority (92\%) of cases were aged $<2$ years [19]. Present results indicate that 30.38
$(5.82+24.56) \%$ were in $0-6$ years age group for AVL, 93.70\% of cases of DST-ZVL were in 0-2 years age group, in agreement with previous observation. While alteration of the pattern of VL case age distribution was observed for MST-ZVL. Previous observation showed that 71.5$86.5 \%$ of cases were in the $0-5$ years age group [19], the case data between 2005-2010 indicated that only 53.51 $(33.61+19.50) \%$ of cases were in the $0-6$ years age group. The reason for a decreasing percentage of cases in infants and young children may be explained by the improvement of nutrition with the economic development or decreasing percentage of children in the total population because of family planning in China.

Sand fly season is from May to September in China. The monthly distribution of cases (Figure 3) showed that cases were identified in all months for AVL and MST-ZVL, while the cases were clustered in the period of September to February of next year for DST-ZVL, indicating that the incubation period of Leishmania infection is shorter in DST-ZVL than in AVL and MSTZVL, consistent with the highest percentage of infantile cases with the state of relative immaturity of cellular immunity.

The present study showed a male predominance among cases, similarly to what has been reported by Willian DSN, et al [32]. We have to investigate whether gender was a risk factor or the result was due to maladjustment of gender in population in China. The reason for the higher susceptibility presented by infants and young children could be explained by the state of relative immaturity of cellular immunity.

Kashgar city of Xinjiang is an AVL endemic area with peridomestic P. longiductus as the vector. From 2000, 


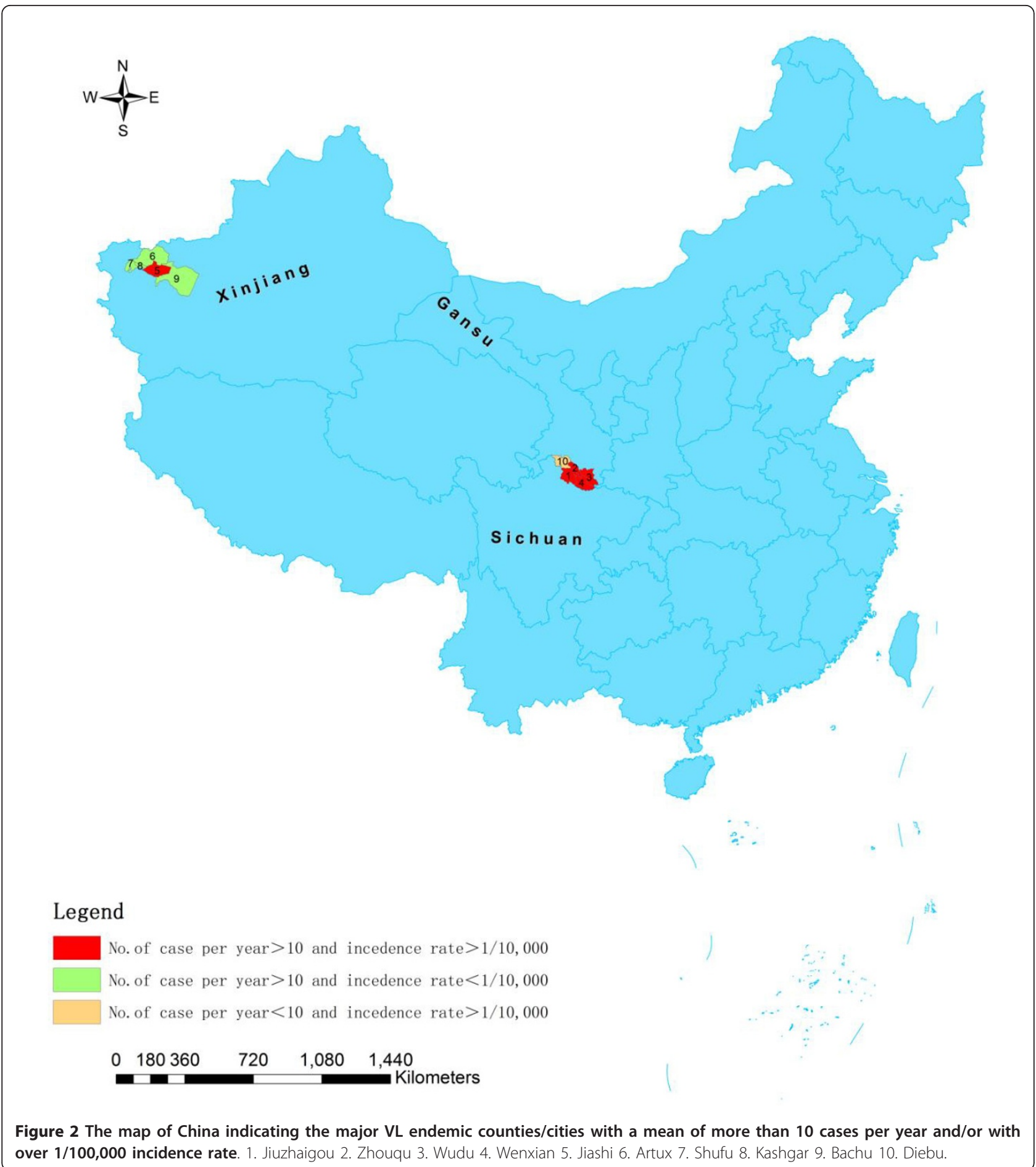

VL cases increased year by year (Figure 4 ). With the implementing of control measure (spraying of insecticides to the house of VL patients and their neighbor) beginning in 2003, cases dropped stepwise (Figure 4). This fact indicated that spraying of insecticides is an effective measure for control of AVL in China.
Jiuzhaigou County of Sichuan is a MST-ZVL endemic area with half of dogs infected by L. infantum [22]. Considering the county is a famous tourism resort, the local authorities advocated killing of dogs beginning in 2005, with a cumulative decrease of half the canine population. Accordingly, the number of human VL case 
Table 5 Age distribution of VL cases in each type of VL

\begin{tabular}{|c|c|c|c|c|c|c|c|c|c|c|}
\hline \multirow[t]{2}{*}{ Age (year) } & \multicolumn{2}{|c|}{ Non-endemic area } & \multicolumn{2}{|c|}{ Endemic area } & \multicolumn{2}{|c|}{ AVL } & \multicolumn{2}{|c|}{ MST-ZVL } & \multicolumn{2}{|c|}{ DST-ZVL } \\
\hline & No. of case & $\%$ & No. of case & $\%$ & No. of case & $\%$ & No. of case & $\%$ & No. of case & $\%$ \\
\hline $0-2$ & 14 & 6.20 & 993 & 44.65 & 23 & 5.82 & 286 & 33.61 & 521 & 93.70 \\
\hline $3-6$ & 9 & 3.98 & 352 & 15.83 & 97 & 24.56 & 166 & 19.50 & 17 & 3.06 \\
\hline $7-14$ & 6 & 2.65 & 310 & 13.94 & 105 & 26.58 & 141 & 16.57 & 9 & 1.62 \\
\hline$\geq 15$ & 197 & 87.17 & 569 & 25.58 & 170 & 43.04 & 258 & 30.32 & 9 & 1.62 \\
\hline Total & 226 & 100 & 2224 & 100 & 395 & 100 & 851 & 100 & 556 & 100 \\
\hline Median age & \multicolumn{2}{|c|}{33.9} & \multicolumn{2}{|l|}{3.7} & \multicolumn{2}{|l|}{12.1} & \multicolumn{2}{|l|}{6.1} & \multicolumn{2}{|l|}{2.1} \\
\hline
\end{tabular}

dropped from 28 cases in 2006 to 7 cases in 2010 (Figure 4). Therefore, Control measures, such as treatment or eradication of infected dogs, or prohibition of maintaining dogs, must be taken against MST-ZVL.

The desert sub-type is unusual and endemic in the northwestern desert regions of China, including Xinjiang, western Inner Mongolia and northern Gansu, where it is considered to be a natural nidus of kala-azar infected wild animals presumably being the source of infection and where the wild species, $P$. wui and $P$. alexandri, are the vectors $[19,23]$. An outbreak of VL in the period of 2008 to 2009 in Jiashi County of Xinjiang, a DST-ZVL endemic area, with the incidence rate increasing more than twentyfold compared to the average annual incidence (Figure 4). After an outbreak occurred we initiated an active surveillance and found that all cases were autochthonous and more than $90 \%$ of cases occurred in infants, while the majority of anthroponotic cases occur among young adults. Most desert sub-type kala-azar cases occur between October and December, whereas the peak of case onset for the anthroponotic type is from April to May, with a secondary peak from September to October. The causative agent for DST-ZVL was identified as L. infantum whose hosts are animals, while little dogs (main reservoir host for ZVL) were found in the outbreak area [16]. We conclude that DST-ZVL is an unusual ZVL. Surprisingly, the number of cases dropped to a normal level in 2010 (only 7 cases were reported after the sandfly season in 2010) with no measures to implement (the vector is wild and reservoir host is unknown). The situation is similar to that which occurred in the Kzyl-Orda region of the Kazakhstan reported by Genis who stated "the dynamics of the incidence is of a 'pulsating' nature and is determined by changes in the status of natural foci of visceral leishmaniasis" [33]. The identification of the reservoir host and study of a control strategy is essential against DST-ZVL in China.

Global warming, globalisation, and the constantly increasing numbers of people involved in long-distance tourism and travel to exotic destinations are likely to increase the number of cases of exotic diseases "imported" to non-endemic countries. The recent literature indicates a sharp increase in imported leishmaniasis cases in developed, non-endemic countries over the last decade, in association with increasing international tourism, military operations, and the influx of immigrants from endemic countries [10,34-37]. In China, imported cases have become a important public health problem with a mean of 40 reported cases per year, and most of cases of exotic VL imported to non-endemic areas was by male labourers on short-term work in endemic areas. Therefore, these people are at particular risk. Appropriate counseling should be provided to the people likely to be exposed to sandflies in endemic areas.

Table 6 Occupational distribution of VL cases

\begin{tabular}{|c|c|c|c|c|c|c|c|c|c|c|}
\hline \multirow[t]{2}{*}{ Group } & \multicolumn{2}{|c|}{ Non-endemic area } & \multicolumn{2}{|c|}{ Endemic area } & \multicolumn{2}{|l|}{ AVL } & \multicolumn{2}{|c|}{ MST-ZVL } & \multicolumn{2}{|c|}{ DST-ZVL } \\
\hline & No. of case & $\%$ & No. of case & $\%$ & No. of case & $\%$ & No. of case & $\%$ & No. of case & $\%$ \\
\hline Infants and young children & 24 & 10.62 & 1339 & 60.21 & 117 & 29.62 & 446 & 52.41 & 542 & 97.48 \\
\hline Students & 9 & 3.98 & 349 & 15.70 & 133 & 33.67 & 158 & 18.57 & 5 & 0.90 \\
\hline Peasants & 0 & 0 & 403 & 18.12 & 117 & 29.62 & 192 & 22.56 & 4 & 0.72 \\
\hline Labourers & 128 & 56.64 & 19 & 0.85 & 0 & 0 & 8 & 0.94 & 1 & 0.18 \\
\hline Workers & 15 & 6.64 & 20 & 0.90 & 3 & 0.76 & 10 & 1.18 & 0 & 0 \\
\hline Officials & 8 & 3.54 & 35 & 1.57 & 6 & 1.52 & 17 & 2.00 & 2 & 0.36 \\
\hline Housewives & 8 & 3.54 & 26 & 1.17 & 14 & 3.54 & 7 & 0.82 & 2 & 0.36 \\
\hline Personnel in service trades & 6 & 2.65 & 5 & 0.22 & 0 & 0 & 4 & 0.47 & 0 & 0 \\
\hline Others & 28 & 12.39 & 28 & 1.26 & 5 & 1.27 & 9 & 1.06 & 0 & 0 \\
\hline$\overline{\text { Total }}$ & 226 & 100 & 2224 & 100 & 395 & 100 & 851 & 100 & 556 & 100 \\
\hline
\end{tabular}


Table 7 Gender distribution of VL cases

\begin{tabular}{lccccc}
\hline Gender & $\begin{array}{c}\text { Non-endemic } \\
\text { area }\end{array}$ & $\begin{array}{c}\text { Endemic } \\
\text { area }\end{array}$ & AVL & $\begin{array}{c}\text { MST- } \\
\text { ZVL }\end{array}$ & $\begin{array}{c}\text { DST- } \\
\text { ZVL }\end{array}$ \\
\hline male & 194 & 1325 & 231 & 504 & 326 \\
\hline female & 32 & 899 & 164 & 347 & 230 \\
\hline rate & $1: 0.165$ & $1: 0.678$ & $1: 0.710$ & 0.688 & 0.706 \\
\hline
\end{tabular}
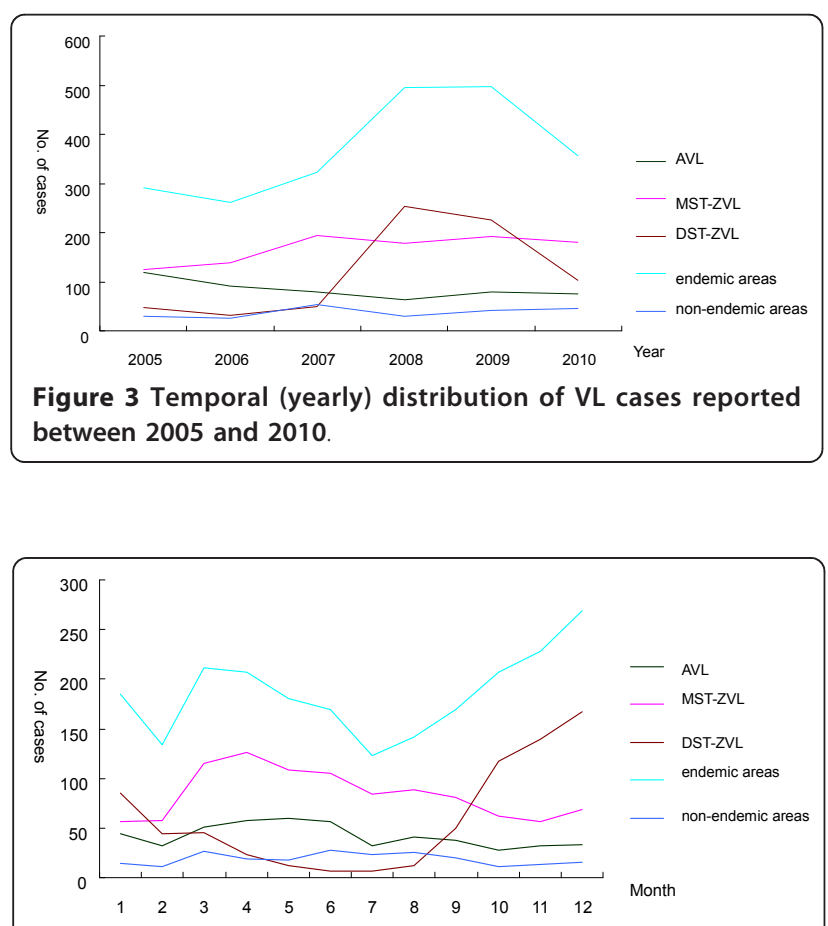

Figure 4 Temporal (monthly) distribution of VL cases reported between 2005 and 2010.

\section{Conclusions}

The results from the present study indicate that the number of visceral leishmaniasis cases and of endemic counties both increased in the period 2005-2010 in China compared to that of the 1990s. Differential control measures must be taken in different endemic areas against incidence increase and endemic area spread.

\section{Acknowledgements}

We are grateful to Dr. Chai Jun-jie and Guan Li-ren for critical comment on the manuscript. This study received financial support from the Chinese $S$ \& $T$ Major Project on Infectious Diseases (Grant No. 2008ZX10004-011 and 2009ZX10004-201)

\section{Author details}

${ }^{1}$ National Institute of Parasitic Diseases, Chinese Center for Disease Control and Prevention; the Key Laboratory of Parasite and Vector Biology of the Chinese Ministry of Health; WHO Collaborating Center for Malaria, Schistosomiasis and Filariasis, Shanghai 200025, People's Republic of China. ${ }^{2}$ Xinjiang Kizilsu Kirgiz Institute of Endemic disease prevention, Artux, 845350, People's Republic of China.

\section{Authors' contributions}

JYW designed and conducted the study, performed data collection/analysis and drafted the manuscript. GC and HTC performed data collection/ statistical analysis. HNZ outlined the draft. CHG and YTY drew the tables and figures. All authors read and approved the final manuscript.

\section{Competing interests}

The authors declare that they have no competing interests.

Received: 8 December 2011 Accepted: 9 February 2012

Published: 9 February 2012

\section{References}

1. World Health Organization: Leishmaniasis: background information. A brief history of the disease. WHO; 2009 [http://www.who.int/leishmaniasis/en]

2. Alvar J, Yactayo S, Bern C: Leishmaniasis and poverty. Trends Parasitol 2006, 22:552-557.

3. Ready PD: Leishmaniasis emergence and climate change. In: $\mathbf{S}$ de la Roque, editor. Climate change: the impact on the epidemiology and control of animal diseases. Rev Sci Tech Off Int Epiz 2008, 27:399-412.

4. World Health Organization: Control of the Leishmaniasis. Geneva: WHO (Technical Report Series 949); 2010, 5-12.

5. Killick-Kendrick R: Phlebotomine vectors of the leishmaniases: a review. Med Vet Entomol 1990, 4:1-24.

6. Guerin PJ, Olliaro P, Sundar S: Visceral leishmaniasis: current status of control, diagnosis, and treatment, and a proposed research and development agenda. Lancet Infect Dis 2002, 2:494-501.

7. Reithinger R, Davies CR: Canine leishmaniasis: novel strategies for control. Trends Parasitol 2002, 18:289-290.

8. Desjeux P: Leishmaniasis. Public health aspects and control. Clinics in Dermatology 1996, 14:417-423.

9. World Health Organization: Control of the Leishmaniasis. Geneva: WHO (Technical Report Series 949); 2010, 104.

10. Ready PD: Leishmaniasis emergence in Europe. Euro Surveill 2010, 15: pii = 19505.

11. Guan LR, Shen WX: Recent advances in visceral leishmaniasis in China. Southeast Asian J Trop Med Pub Health 1991, 22:291-298.

12. Zhou XN, Lv S, Yang GJ, Kristensen TK, Bergquist NR, Utzinger J, Malone JB: Spatial epidemiology in zoonotic parasitic diseases: insights gained at the 1st International Symposium on Geospatial Health in Lijiang, China, 2007. Parasit Vectors 2009, 2:10.

13. Guan LR, Qu JQ, Chai JJ: Leishmaniasis in China-present status of prevalence and some suggestions on its control. End Dis Bull 2000, 15:49-52 (in Chinese).

14. Wang JY, Feng Y, Gao CH, Jin CF, Chen SB, Zhang CJ, He JP, Yang CM, Yang YT, Bao YF: Asymptomatic Leishmania infection in human population of Wenxian County, Gansu Province. Chin J Parasitol Parasitic Dis 2007, 25:62-64 (in Chinese).

15. Guan LR, Zuo XP, Yimamu : Reemergence of visceral leishmaniasis in Kashi Prefecture, Xinjiang. Chin J Parasitol Parasitic Dis 2003, 21:285.

16. Wang JY, Gao CH, Yang YT, Chen HT, Zhu XH, Lv S, Chen SB, Tong SX, Steinmann P, Ziegelbauer K, Zhou XN: An outbreak of the desert sub-type of zoonotic visceral leishmaniasis in Jiashi, Xinjiang Uygur Autonomous Region, People's Republic of China. Parasitol Int 2010, 59:331-337.

17. Wang J, Peng XD, Guo YK, Yang GY: A preliminary survey of epidemicity of ala-azar in Xinjiang Urghur Autonomous Region. J Epidemiol 1966, 4:30-32 (in Chinese).

18. Lu HG, Zhong L, Guan LR, Qu JQ, Hu XS, Chai JJ, Xu ZB, Wang CT, Chang KP: Separation of Chinese Leishmania isolates into five genotypes by kinetoplast and chromosomal DNA heterogeneity. Am J Trop Med Hyg 1994, 50:763-770.

19. Guan LR: Current status of kala-azar and vector control in China. Bull World Health Organ 1991, 69:595-601.

20. Wang JY, Chen SB, Gao CH, Jin CF, Feng Y, Zhang ZJ: Survey on the Leishmania infantum asymptomatic infection in dogs in Wenxian county of Gansu Province. Chin J Zoonoses 2006, 22:734-737 (in Chinese).

21. Wang JY, Ha Y, Gao CH, Wang Y, Yang YT, Chen HT: The prevalence of canine Leishmania infantum infection in western China detected by PCR and serological tests. Parasit Vectors 2011, 4:69. 
22. Chai JJ, Guan LR: Leishmaniasis and phlebotomine sandflies in the Xinjiang Uygur Autonomous Region, the People's Republic of China Urumqi, Xinjiang People's Press; 2006.

23. Yisilayin O, Jin CF, Zuo XP, Gu DA, Lan QX, Tong SX, Li X, Zhang Yi: A Newly Identified Endemic Area of Visceral Leishmaniasis in Minfeng County of South Xinjiang I. Epidemiological Survey. Chin J Parasitol Parasit Dis 2008, 26:128-131.

24. Guan LR, Zuo XP, Yimamu: Reemergence of visceral leishmaniasis in Kashi Prefecture, Xinjiang. Chin J Parasitol Parasitic Dis 2003, 21:285 (in (hinese).

25. Wang L, Wang Y, Jin S, Wu Z, Chin DP: Koplan JP: Emergence and control of infectious diseases in China. Lancet 2008, 372:1598-1605.

26. Desjeux $P$ : The increase in risk factors for leishmaniasis worldwide. Trans R Soc Trop Med Hyg 2001, 95:239-243.

27. Gabutti G, Balestra G, Fkego G, Crovari P: Visceral leishmaniasis in Liguria, Italy. Lancet 1998, 351:1136.

28. Punda-Polić V, Sardelić $\mathrm{S}$, Bradarić N: Visceral leishmaniasis in southern Croatia. Lancet 1998, 351:188.

29. World Health Organization: Leishmaniasis and leishmania/HIV coinfection. WHO report on global surveillance of epidemic-prone infectious diseases 2000, Report no. WHO/CDS/CSR/ISR/2000.1. Geneva.

30. Wang JY, Gao CH, Yang YT, Bao YF: Evaluation of a repetitive DNA sequence of Leishmania on the identification of Leishmania isolates in China. Chinese J Zoonoses 2005, 21:304-308.

31. Wu B, Qu JQ: Karyotype analysis of Leishmania isplates in China. Chin J Parasitol Parasit Dis 1998, 16:425-431.

32. da Silva Nunes Willian, Araújo SR, Calheiros CM: Epidemiological profile of leishmaniasis at a reference service in the state of Alagoas, Brazil, from January 2000 to September 2008. Braz J Infect Dis 2010, 14:342-345.

33. Genis DE: Epidemiological features of visceral leishmaniasis in the northern part of the distribution area (Kzyl-Orda region of the Kazakh SSR). Medskaya Parazit 1978, 47:15-21, (in Russian).

34. Pavli A, Maltezou HC: Leishmaniasis, an emerging infection in travelers. Int J Infect Dis 2010, 14:e1032-1039.

35. Stark $D$, van Hal $S$, Lee $R$, Marriott $D$, Harkness J: Leishmaniasis, an emerging imported infection: report of 20 cases from Australia. J Travel Med 2008, 15:351-354.

36. Górski S, Wiercińska-Drapało A: Visceral leishmaniasis as a threat for nonendemic countries. Wiad Parazytol 2009, 55:195-200, (in Polish).

37. Malik AN, John L, Bruceson AD, Lockwood DN: Changing Pattern of Visceral Leishmaniasis, United Kingdom, 1985-2004. Emerg Infect Dis 2006, 12:1257-1259

doi:10.1186/1756-3305-5-31

Cite this article as: Wang et al: Current epidemiological profile and features of visceral leishmaniasis in People's Republic of China. Parasites \& Vectors 2012 5:31.

\section{Submit your next manuscript to BioMed Central and take full advantage of:}

- Convenient online submission

- Thorough peer review

- No space constraints or color figure charges

- Immediate publication on acceptance

- Inclusion in PubMed, CAS, Scopus and Google Scholar

- Research which is freely available for redistribution

Submit your manuscript at www.biomedcentral.com/submit
Biomed Central 